\title{
AC 2008-1243: ENHANCING STUDENT LEARNING THROUGH STATE-OF- THE-ART SYSTEMS LEVEL DESIGN AND IMPLEMENTATION: THE DEVELOPMENT OF A LOWER DIVISION LEARNING MODULE
}

\section{James Harris, California Polytechnic State University}

James G. Harris received his BS and MS in EE from UCB and the PhD in EE from Syracuse University. He was an Assistant Professor at Howard University, and an Associate Professor at the University of the District of Columbia, both in Washington, D.C. He is a Professor with the Department of Electrical Engineering, and the Computer Engineering Program at Cal Poly in San Luis Obispo, CA. He served as the Department Head of the EE Department from 1982-89 and the Director of the Computer Engineering Program from 1993-97, and starting in January 2008, he is serving as Director of the Computer Engineering Program. From 1990-92, he was a Program Director in the Division of Undergraduate Education at the National Science Foundation in Washington, D.C. He worked for TRW in Redondo Beach, CA for 11 years, primarily on signal processing projects. He is a member of IEEE, ASEE, ACM, AAAS, and SHOT.

\section{Dominic Dalbello, Allan Hancock College}

Dominic J. Dal Bello received his B.S. and M.S. degrees in Mechanical Engineering from UC Santa Barbara. He is currently Assistant Professor of Engineering at Allan Hancock College, a California community college in Santa Maria, where he teaches Statics, Dynamics, Strength of Materials, Material Science, Circuit Analysis, Circuits and Devices, and Matlab. In Spring 2006, he was the first recipient of the Allan Hancock Foundation Outstanding Faculty Award. Professor Dal Bello also teaches at UC Santa Barbara during the summer session. He worked for four years analyzing structures for Clamshell Buildings in Ventura, CA. He is a member of ASEE and ASME.

\section{Jianbiao Pan, California Polytechnic State University}

Dr. Jianbiao (John) Pan is an assistant professor in the Department of Industrial and Manufacturing Engineering at Cal Poly, San Luis Obispo, CA. After completing a $\mathrm{PhD}$ at Lehigh University in Industrial Engineering in 2000, he joined the optoelectronics center at Lucent Technologies/Agere Systems as a member of technical staff. He received a M.E degree in Manufacturing Engineering from Tsinghua University, Beijing, China, and a B.E. degree in Mechatronics from Xidian University, Xian, China. Dr. Pan's research interests include electronics packaging, optoelectronics packaging, surface mount assembly, hybrid microelectronics, design and analysis of experiment, and computer aided manufacturing. He has been a Society of Manufacturing Engineers (SME) advisor on Electronics Manufacturing, and served on the National Technical Committee for the International Microelectronics and Packaging Society (IMAPS), and as Chair of SME Electronics Manufacturing Engineering Certification Committee. He is a senior member of IEEE, IMAPS, and SME, and a member of Sigma Xi and ASEE. Dr. Pan is a recipient of the 2004 M. Eugene Merchant Outstanding Young Manufacturing Engineer Award from the Society of Manufacturing Engineers (SME). He is a Highly Commended Winner of the Emerald Literati Network Awards for Excellence 2007. He is also an invitee of the National Academy of Engineering (NAE) Frontiers in Engineering Symposium in 2007.

\section{Albert Liddicoat, California Polytechnic State University}

Albert A. Liddicoat received his M.S. and Ph.D. degrees in Electrical Engineering and his M.S. degree in Engineering Management from Stanford University in 1996, 2002 and 1999, respectively. Dr. Liddicoat worked for IBM's Storage Technology Division from 1990 until 2002 where he held many positions in disk drive development including: servo system test and integration, ASIC development, system electronics and architecture, program management, and business line management. Currently, he is the Forbes Associate Professor and the Director of the 
Computer Engineering Program at Cal Poly State University in San Luis Obispo. His research interests include computer architecture, computer arithmetic, networks, and re-configurable computing. 


\title{
Enhancing Student Learning Through State-of- the-Art Systems Level Design and Implementation: The Development of a Lower Division Learning Module
}

\begin{abstract}
The Cal Poly/Allan Hancock team is developing a learning module that will allow all lower division engineering students to design, fabricate, assemble, and test an electronic system implemented on a printed circuit board (PCB). All the services necessary to perform this laboratory experiment will be provided with low-cost vendors available on the . The learning module is being developed so that it can be integrated into the existing electrical engineering lower division courses that are required by all engineering students. The laboratory learning module will use operational amplifiers (op amp), resistors, capacitors and other common electronic components to study the theory of op am circuits, and to apply these circuits to the interfacing of electronic signals with the physical world. The learning module will replace two existing laboratory experiments on op amps with a five week exercise. After lecture on the theory, the five week exercise will consist of one week of laboratory introducing the PCB technology and the PCB design tool. Outside of class, the students will submit their designs (after instructor review) to a vendor for fabrication, and order their parts. After about three weeks, the students are expected to have received the fabricated PCB and to have assembled the parts on the PCB. On the last week, they will test their board and perform the experiment. Thus, this learning module will be compatible with current course/lab schedules, and could be conveniently incorporated into an existing course/lab to meet and extend the existing laboratory learning objectives.
\end{abstract}

\section{Introduction}

In today's global environment it is imperative that engineering graduates are prepared to enter the workforce with the skills necessary to make immediate contributions. A review of that imperative identified a gap in the engineering curricula: there is a lack of "systems" level design experience that requires engineering students to synthesize what they have learned in their curriculum and extend their knowledge outside their field of study through independent learning.

In an attempt to address this issue in the computer engineering curriculum at Cal Poly, we are building a pipeline in the curriculum to properly prepare and engage students in project-based learning activities. More specifically, we are developing a new electronics design and manufacturing course, a new introduction to systems design course, and incorporating a scalable solution to project-based learning into the curriculum ${ }^{1}$. The project-based learning experience is aimed to provide a multidisciplinary environment to design the hardware and software components of a system while industrial and manufacturing engineering students fabricate and assemble the boards. This experience in the undergraduate computer engineering curriculum will better prepare students to enter the workforce after obtaining a four-year degree and to better meet their employers' expectations. 
To support this plan we have partnered with Allan Hancock Community College to develop a lower-division curriculum module to make Printed Circuit Board (PCB) design and manufacturing experience available to a greater audience. The Cal Poly/Allan Hancock team is developing learning modules that will allow all lower division engineering students to design, fabricate, assemble, and test an electronic system implemented on a PCB. All the services necessary to perform this laboratory experiment will be provided with low-cost vendors available on the . The learning modules are being developed so that they can be integrated into the existing electrical engineering lower division courses that are required by all engineering students.

After discussing the background for this work, this paper presents the curriculum requirements for incorporating two learning modules: a tutorial for PCB development and a laboratory module to substitute for two existing lab experiments. Then we discuss the development of the tutorial module, and the development of the proposed laboratory experiment. Next, we discuss the status and plans for this project, and finally, we present our conclusions.

\section{Background}

There are only 24 ABET accredited manufacturing engineering programs and 35 ABET accredited manufacturing technology programs in the United States out of around 300 engineering colleges. Therefore, it is reasonable to assume that most engineering graduates do not get direct laboratory experience in printed circuit board electronic manufacturing. Recognition of this fact led the team working on integrating system design into the engineering curriculum to develop curricular modules to address this situation, modules that could be used by all lower division engineering programs, including those at community colleges.

The Electrical Engineering (EE) program at Cal Poly has been very fortunate to have had a manufacturing curriculum for over 50 years. This program evolved into the present Manufacturing Engineering (MfgE) program, which was accredited in 1996. Even prior to this, $\mathrm{EE}$ and $\mathrm{ME}$ programs required majors to take lower division courses in manufacturing processes relevant to their disciplines. In fact, the EE program required students to use PCB technology to satisfy their senior project requirements up until around 1990. The EE department provided a PCB fabrication service for single and double sided boards to support this requirement. Students provided drafting masks for the fabrication of their PCB board design. Thus, Cal Poly has a rich history in integrating manufacturing technology into the engineering curriculum, and this history provided the foundation for the present project to integrate system design into the curriculum.

Reviewing the literature for the integration of manufacturing technology into the engineering curriculum for the last two decades is illuminating and provides the foundation for this project. In the 1990's, engineering programs which had either manufacturing technology, or manufacturing engineering programs, as part of their engineering colleges, were proposing the integration of electronic manufacturing technology into the electrical and computer engineering

curriculum $^{2-10}$, either with existing or new laboratory facilities. This trend continued into this decade with the development of new laboratories, most associated with new manufacturing engineering programs ${ }^{11-14}$. 
Concurrent with this curricular development, new services for PCB fabrication and for acquiring electronic parts were being provided via the ${ }^{15,16}$. These new services allowed university engineering programs which did not have manufacturing laboratory facilities and convenient access to electronic parts to now have low-cost, fast, and convenient access to PCB fabrication and assembly for their students. In addition, a number of the PCB fabrication services had tutorial material at their websites that allowed new customers to conveniently enter their PCB designs over the , and to submit them for fabrication. An example is PCB $123^{17}$ which introduces the concept of PCB design and manufacturing, and presents a step-by-step procedure to enter a design for fabrication. However, most of these websites are specific to a particular PCB fabricator, and do not provide the industry standard Gerber file output for the PCB design that allows submission of the PCB design to other vendors.

Recognizing this new resource, the members of the project team realized that PCB technology is available to all lower division engineering students, not just electrical and computer engineering students who have access to electronic manufacturing laboratories at their college. To ensure that the results of the project could be universally disseminated to any program that has web access, the team members include an engineering faculty member from a community college. This new resource also is accessible by high school and middle school students, and therefore, there is a plan to add a high school teacher to the project team during summers. The concept of outreach to the K-12 programs using electronic manufacturing has precedence for a project by Reid at IUPUI ${ }^{18}$.

\section{Curricular Requirements}

The purpose of this project is to integrate the design, fabrication, assembly, and testing of PCB electronic systems into the curriculum of all lower division engineering students. To accomplish this, the team partitioned the initial concept of one learning module into the development of two learning modules: (1) a tutorial learning module that will provide the student with foundational knowledge of PCB technology and the resources available on the web, and with a procedural template for developing a PCB board; and (2) a laboratory learning module designed to replace two standard experiments on operational amplifiers (op-amps) which we believe are taken by all engineering students in the lower division.

The development of each of the learning modules will be discussed below. The plan is to integrate these learning modules into the lower division electrical engineering service course taken by all engineering majors. The calendar span of this curriculum innovation is five weeks, and it will replace two laboratory experiments on op-amps (it is our assumption that all service electrical engineering laboratory courses include two experiments on op-amps). Preceding the laboratory work, there should be lectures on the principles of electronics manufacturing, standard material in most texts ${ }^{19}$. After lecture on the theory, a one week laboratory will be used by the students to perform the tutorial learning module, which introduces the student to PCB technology and a PCB computer-aided-design tool such as DipTrace. The outcome of the tutorial is a PCB design and manufacturing file for a basic continuity tester. It is expected that the student tutorial PCB design layout will be reviewed at this time, and after successful review by the course instructor, the student will be given a PCB board and the parts to assemble the tutorial circuit. Soldering equipment will be required at each workstation for the next step at approximately $\$ 50$ 
per workstation. The students will assemble and test their PCB implementation. After completion of the tutorial learning module, the students will begin working on the laboratory learning module for the next four weeks.

The laboratory learning module presents the student with an op-amp project PCB design and laboratory experiment. Most of the work in the next three weeks will be performed outside the laboratory; some brief time in the laboratory will be used to review the students' progress. The students will submit their PCB design (after instructor review) to a vendor such as PCBExpress for fabrication, and order their parts. At the end of the three weeks, the students are expected to have received the fabricated PCB and to have assembled the parts on the PCB. During the last week in this laboratory experiment, they will test their board and perform the op-amp experiment. Since the use of the PCB facilitates extensive connections, the laboratory time allocated to the op-amp project should be very productively used, i.e., very little time should be necessary for construction and debugging the wiring. Thus, this learning module should be compatible with current course/lab schedules, and could be conveniently incorporated into an existing course/lab.

In summary, the curricular innovation only requires an engineering program to provide a soldering station in the laboratory (estimated to be less than $\$ 50$ per workstation), to provide the student with the tutorial PCB and parts (estimated to be less than $\$ 10$ per student - part of their lab fee), and to adopt the laboratory learning module by substituting it for an existing lab on opamps (costs for this lab project paid for by the students, and estimated to be less than \$40).

\section{Tutorial Modules Development}

An extensive survey was performed on existing PCB computer-aided-design tools to ascertain their applicability to an academic environment, specifically lower division engineering students. The output data from that survey were presented in a criteria matrix, which included such criteria as cost, availability of tutorial material, estimated student learning time, and output format support for Gerber files. As a result of that effort, DipTrace was chosen as the PCB design tool for the project ${ }^{20}$. DipTrace has an evaluation version that is free, but the free version does not provide a Gerber file output; however, the output can be used as an input to the vendor for PCB fabrication. A version which does produce a Gerber file, and hence allows other PCB fabrication vendors to be used, can be purchased for a nominal fee (around $\$ 125$ per seat for academic institutions). Students can use the free version of the DipTrace tool at their individual lab stations and share a single seat of the upgraded DipTrace tool to generate Gerber output files for their projects.

The continuity tester project used in the current electronics manufacturing laboratory course IME 157 at Cal Poly is used as the basis for the tutorial learning module. It is a relatively simple PCB design with a small number of diverse component parts, and can be used by the students to check electrical connections for continuity; see Figure 1 for the schematic, Table I for the parts list (BOM, bill of materials), and Figures 2 for a photo of the PCB. 


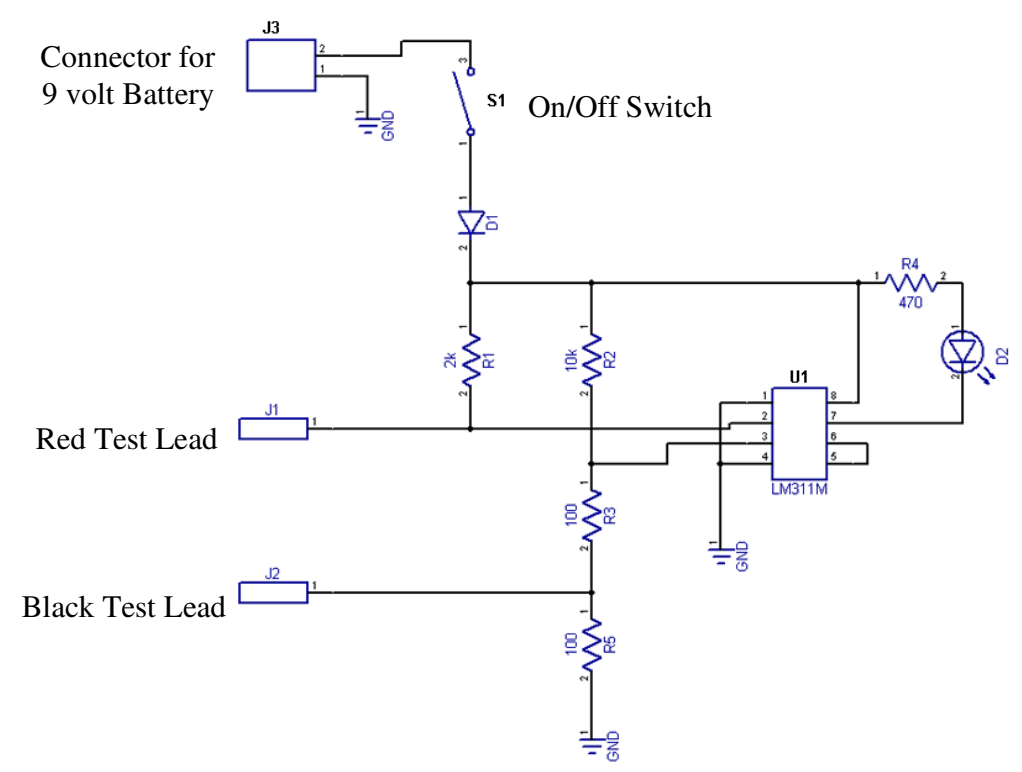

Figure 1 Schematic of Continuity Tester

Table I: Bill of Materials of the Continuity Tester

\begin{tabular}{|c|c|c|l|}
\hline ITEM & QTY. & REF. & \multicolumn{1}{|c|}{ DESCRIPTION } \\
\hline 1 & 1 & D1 & Diode, 1N914 \\
\hline 2 & 1 & D2 & LED, red, SIZE 1-3/4, Panasonic LN21RPHL \\
\hline 3 & 1 & J1 & Test lead, red, 12"L \\
\hline 4 & 1 & J2 & Test lead, black, 12"L \\
\hline 5 & 1 & J3 & Cable, 9V battery snap \\
\hline 6 & 1 & R1 & Resistor, 2 K ohm 1/4W, 5\% tolerance \\
\hline 7 & 1 & R2 & Resistor, 10 K ohm 1/4W, 5\% tolerance \\
\hline 8 & 1 & R3 & Resistor, 100 ohm 1/4W, 5\% tolerance \\
\hline 9 & 1 & R4 & Resistor, 470 ohm 1/4W, 5\% tolerance \\
\hline 10 & 1 & R5 & Resistor, 100 ohm 1/4W, 5\% tolerance \\
\hline 11 & 1 & S1 & Switch, Panasonic EVQ-PAC09K \\
\hline 12 & 1 & U1 & IC, LM311M \\
\hline
\end{tabular}




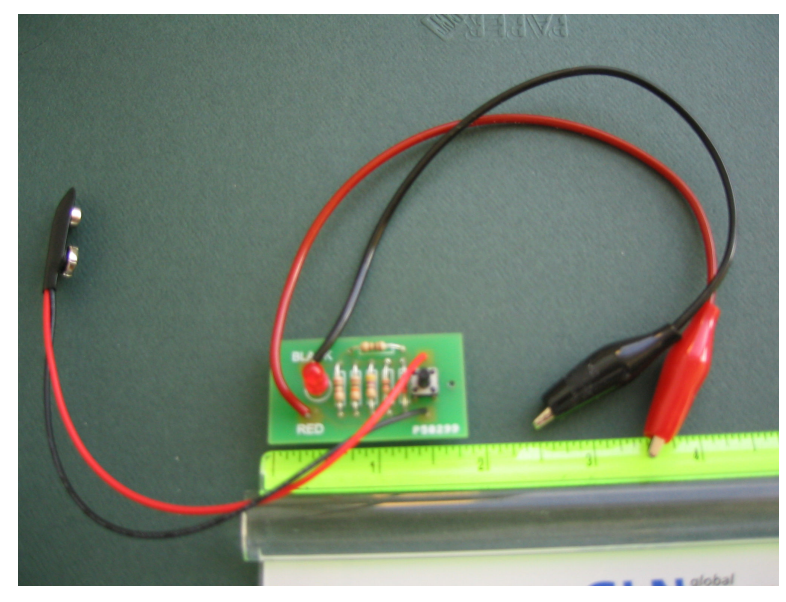

Figure 2 Top View of Continuity Tester

\section{Laboratory Module Development}

The curriculum for most engineering majors contains a requirement to take a set of courses in electrical engineering which generally cover circuits, electronics and electrical energy conversion. Typically there are concurrent required laboratories to accompany the lecture courses. These engineering courses are usually available to students in the lower division (i.e., the prerequisite courses are typically the completion of the calculus-based physics course in electricity and magnetism and the completion of the mathematics course in differential equations). The theory and application of operational amplifiers are one of the standard topics presented in these required engineering courses.

In the laboratory component, it usually takes two laboratory periods to cover both the theory and principles of operation of the operational amplifier, and the application of the operational amplifier to diverse linear and non-linear circuits. The student generally must be allocated laboratory time to connect and debug the wiring of as many as eight circuits in the two, three hour laboratory periods, e.g., inverting amplifier, non-inverting amplifier, voltage follower (buffer), summing amplifier, integrator/low-pass filter, voltage comparator, and D/A converter. The project team chose the operational amplifier laboratory experience to insert the PCB material for the following reasons: learning material on operational amplifiers would not be lost due to increased efficiency because of PCB implementation of circuits; if two weeks are allocated, then it is not necessary to remove other laboratory projects - just rearrange the schedule to accommodate three weeks between the two periods devoted for the laboratory learning module; student access to necessary resources outside the scheduled lab such as services; because of their wide application, using operational amplifiers to motivate the study of PCB technology allows the student to immediately apply the technology to their discipline in engineering, e.g., ME's can use knowledge to develop instrumentation circuits.

Therefore, after the students have completed the tutorial module during the first laboratory period, they will begin to design their operational amplifier PCB, and the corresponding op amp material can be presented in lecture. The requirements of the design are to provide a circuit that can be used to implement a diverse set of operational amplifier circuits using simple interconnections though the use of wire-wrap connections to headers, and the use of standard 
power and instrumentation connections. Thus, the PCB contains electronic components including op-amps, resistors, capacitors, headers, junction connectors, and dual-in-line (DIP) components such as a 74LS163 4-bit counter for the D/A circuit. Figure 3 presents a photo of the prototype of the PCB design.

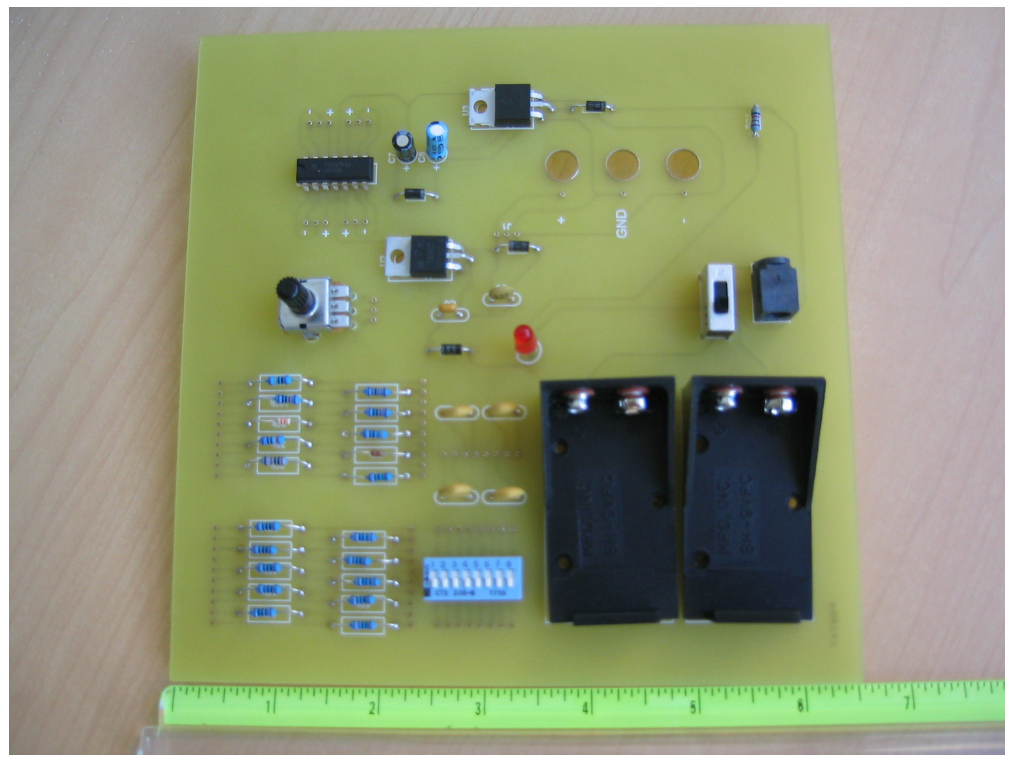

Figure 3 Prototype op-amp PCB for Laboratory Learning Module

\section{Status and Plans}

As of January 2008, the tutorial learning module has a draft version of its web-based material, a prototype PCB product produced from that draft version, and an initial version of the instructor materials to support its dissemination. The laboratory learning module is based upon two existing laboratory experiments in EE 361, Electronics Laboratory: Operational Amplifiers I and II. The set of requirements for the PCB design has been drafted. Based upon those requirements and using the facilities available in the electronics manufacturing laboratory, a one-sided PCB has been designed, fabricated, and assembled. This prototype PCB is currently being tested to verify the results of the two experiments with those obtained using the current technology, a commercial designer box with protoboard and power supply connections.

The draft version of the tutorial learning module for the continuity tester will be used by selected students (supported by the NSF-CCLI grant) at Allan Hancock Community College and at Cal Poly during the 2008 Winter and Spring terms. A formative assessment will be performed on this experience, and used to revise the materials. In particular, the logistical requirements and cost associated with performing the work, and the amount of time that students need to complete the work presented in the module will be ascertained. In summer 2008, modifications to the tutorial learning module will be made. In addition, support is being sought to have a local high school teacher spend the summer working on the project. The high school teacher will assist 
with the review and revision of the tutorial learning module, as well as the evaluation of the material for its potential incorporation into their educational program.

During the winter and spring terms of 2008, development of the laboratory learning module for the op amp experiment will continue. Students working on the project at both colleges will develop a PCB using the services provided over the . As assessment of the logistics and of the costs of accessing these services will be obtained. An additional assessment will be performed on the time requirement of the students to develop the PCB and to perform all the operational amplifier experiments. During the summer of 2008, this assessment data will be used to review and revise the laboratory learning module, and to develop the instructor material for incorporating the laboratory learning module into the curriculum.

Plans are that both the tutorial learning module and the laboratory learning module will be classroom tested at Cal Poly and Allan Hancock Community College in Fall 2008. Based upon an assessment of those activities, the modules will be reviewed and revised. After this revision, the material will be made available to San Jose State University for their faculty to review and consider for incorporation into their curriculum. Both modules and their associated instructor material will be available from a public website for other programs to use.

\section{Conclusions}

The development of a tutorial learning module and a laboratory learning module for the lower division engineering curriculum will introduce all engineering majors to current electronic manufacturing technology, and allow them to design electronic systems using PCB technology. This curricular innovation is available to all lower division programs because it relies on the availability of fabrication services and parts procurement through the . The laboratory learning module is designed to maximize its potential to be incorporated into all electrical engineering service courses through it use of the study of operational amplifier circuits. The tutorial learning module currently is being classroom tested and assessed. In addition, the tutorial learning module will be evaluated for applicability to high school students. The laboratory learning module is under development, and the plans are to begin classroom testing and assessment in Fall 2008. After the completion of the assessment activities, the tutorial learning module and the laboratory learning module will be available to all engineering programs by being accessible via a public website.

\section{Acknowledgement}

This work is sponsored by the National Science Foundation Course, Curriculum, and Laboratory Innovation (NSF-CCLI) program, under award DUE-0633363. The authors wish to acknowledge the contribution to this project by their students: Ron Sloat, Edward Adams and Greg LaCaille. 


\section{Bibliography}

1. Liddicoat, Albert; Pan, Jianbiao; Harris, James G.; Slivovsky, Lynne; Curricular Enhancement to Support ProjectBased Learning in Computer and Electrical Engineering; ASEE Annual Conference Proceedings; 2008.

2. Gwozdz, Peter S.; Semiconductor Manufacturing Education at San Jose State University; 3rd Annual International Semiconductor Manufacturing Science Symposium held in Conjunction with SEMICON/West ISSMSS 91; 1991.

3. Strano, Joseph; Introducing Freshman to Guided Design in Electrical Engineering utilizing a Laboratory Measurement Approach; ASEE Annual Conference Proceedings; 1995.

4. Allen, Emily L.; Green, Evan D. H.; Vanasupa, Linda S.; Cooking without Recipes: A Case Study for an OpenEnded Laboratory Experience in Semiconductor Processing; ASEE Annual Conference Proceedings;1996.

5. Braun, Christopher G.; An Electronics Prototyping Facility for Undergraduate Electronics Laboratories; ASEE Annual Conference Proceedings; 1996.

6. Rizkalla, Maher E.; O'Loughlin, Carol L.; Yokomoto, Charles F.; Development of an Interdisciplinary Undergraduate Laboratory for a Course on Design and Manufacture of Surface Mount Printed Circuit Board Assemblies; ASEE Annual Conference Proceedings;1997.

7. Braun, Christopher G.; Making Things Real in Electronics Laboratories; Journal of Engineering and Applied Science; v2 pp.845-848; 1997.

8. Koretsky, Milo D.; Rochefort, Willie E.; Reiter, William F.; Interdisciplinary Program and Laboratory for Printed Circuit Board (PCB) Design and Manufacturing; ASEE Annual Conference Proceedings; 1997.

9. Reid, Kenneth; Cooney, Elaine; Development and Delivery of an Industry Course in Electronics and Electronics Manufacturing; ASEE Annual Conference Proceedings; 1999.

10. Rizkalla, Maher E.; Yokomoto, Charles F.; Miled, Zina Ben; SAlama, Paul; El-Sharkawy, Mohamed; A

Multidisciplinary Electronic Manufacturing Undergraduate Laboratory for the Design and Manufacture of DSP and Computer Based ASIC Systems; ASEE Annual Conference Proceedings;1999.

11. Berg, William M.; Boughton, Morris W.; Enhanced Suitcases for Upper Division Electronics Laboratories; ASEE Annual Conference Proceedings; 2001

12. McLaren, Timothy S.; A Microelectronic Fabrication and Packaging Learning Laboratory for Manufacturing Engineers; ASEE Annual Conference Proceedings; 2001.

13. Blackwell, Glenn R.; Laboratories for the Design and Assembly of Electronic Devices using Surface Mount Components; ASEE Annual Conference Proceedings; 2005.

14. Yang, D. G.; A New Educational Curriculum for Microelectronic Manufacturing Engineering Program; Proceedings of IEEE Electronic Components and Technology Conference; 2005.

15. examples of PCB services on web: www.sunstone.com/; www.fast-pcb.com/; www.pcb007.com; (use a web search engine such as google to find more).

16. examples of electronic parts vendors on web: www.mouser.com; www.digikey.com; www.jameco.com; (use a web search engine such as google to find more).

17. example of PCB tutorial and design entry: www.pcb123.com; (use a web search engine such as google to find more).

18. Reid, K. J.; Outreach to K-12 Programs with a Mobile Laboratory: Hands-On Electronics Manufacturing; Proceedings - Frontiers in Education Conference; 2001.

19. Rizzoni, Giorgio; Principles and Applications of Electrical Engineering 4th Ed.; McGraw-Hill; 2004

20. see http://www.diptrace.com/; visited 12/26/07. 